Revista Brasileira de Fisiologia do exercício 2018;17(1):1-2

\title{
EDITORIAL \\ Novas discussões sobre periodização e monitoramento do treinamento
}

\author{
Radamés Maciel Vítor Medeiros* \\ *Professor Doutor do Centro Universitário do Rio Grande do Norte (UNI-RN),
}

Correspondência: radames.medeiros@unifesp.br

O treinamento esportivo é caracterizado como um processo complexo, cujo resultado final pode ser atingido diante da união de diversos fatores, sejam eles associados ao conhecimento de conteúdo teórico acerca do treinamento, ou diante da arte de intuição do treinador. Assim, o desenvolvimento relacionado ao processo de preparação esportiva está diretamente relacionado às evidências empíricas da prática do treinador e a fundamentação teórico-científica presente nas diversas áreas relacionadas às ciências do esporte [1].

Mesmo diante dos conceitos, inúmeros analistas, pesquisadores e profissionais do meio esportivo permanecem com o questionamento: "Como poderia ser planejado o treinamento mais eficiente para o desempenho do atleta?" No processo histórico da humanidade, Manso, Valdivieso e Caballero [1] descrevem uma síntese sobre o treinamento esportivo em três fases ou etapas: a) desde a sua origem até o ano de 1950, quando se inicia a sistematização do treinamento esportivo; b) a segunda fase atinge os anos até 1970, momento em que se questionaram os modelos clássicos de planejamento e apareceram novas propostas ou modelos; c) a terceira etapa, que se estende até os dias atuais, apresenta a vivência de uma grande evolução do conhecimento nesta área de pesquisa.

Tal evolução pode ser observada a partir dos modelos teóricos criados para o planejamento e periodização do treinamento esportivo. O modelo tradicional (ou moderno), divulgado pelo cientista russo professor Doutor Leev Pavlovtchi Matveev nos anos 50, tomou grande repercussão mundial e popularizou as premissas relacionadas à periodização, fundamentando-se na teoria da Síndrome Geral da Adaptação. A partir disso, o modelo de periodização e a sua estruturação lógica de preparação do atleta a partir da hierarquia de ciclos de treinamento e unidades tornou-se uma ferramenta universal para o planejamento e análise na formação de atletas em diversos esportes, e sob diferentes níveis de desempenho.

Apesar de amplamente aceita, a abordagem da periodização do treinamento merece importante atenção, especialmente porque os aumentos aleatórios de variáveis como volume, intensidade ou frequência podem aumentar a probabilidade de lesões e sintomas de overtraining. Neste sentido, observa-se que o papel da investigação científica neste processo está se tornando mais importante, a fim de prescrever programas de treinamento ideais que impeçam o risco de lesão e propicie alcançar o desempenho desejado.

Em estudo publicado recentemente, Loturco e Nakamura [3], discutindo as controvérsias e debates acerca das bases conceituais da periodização do treinamento, trazem duas questões importantes: 1) o papel da periodização em otimizar o desempenho real durante a fase de pico de desempenho, planejada previamente; 2) como identificar as melhores estratégias para controlar e melhorar a capacidade esportiva dos atletas.

Segundo estes autores, ao examinar o papel do conceito de periodização em alcançar o máximo desempenho específico nos eventos específicos selecionados pelo atleta / equipe (jogos amistosos e competitivos, por exemplo), importantes desvantagens emergem: taxas baixas de eficiência nos resultados de melhor desempenho pessoal ao longo do ciclo competitivo.

A partir dessa abordagem, novas perspectivas na literatura são encontradas para 0 treinamento esportivo. Para alguns, a periodização permanece como importante ferramenta de planejamento em preparação para os ciclos competitivos, porém associada ao monitoramento das cargas de treino. Baseado nas respostas de cada atleta e da equipe ao que foi programado, o profissional poderá compreender a diferença entre as expectativas e a realidade para cada momento, readequando o planejamento e buscando sempre a manutenção do máximo de desempenho. 
Referências

1. Gomes AC. Treinamento Desportivo: Estruturação e Periodização. Porto Alegre: Artmed; 2009.

2. Manso JMG, Valdivielso MN, Caballero JAR. Planificación del entrenamiento deportivo. Madrid: Gymnos; 1996.

3. Loturco I, Nakamura FY. Training periodization: an obsolete methodology? Aspetar Sports Medicine Journal 2016;5:110-5. 